\title{
Segurança no Trabalho em um Canteiro de Obras: Percepções dos Operários e da Gerência
}

\author{
Tarcisio Abreu Saurin, Engo Civil, M.Sc. \\ Doutorando do PPGEP/UFRGS (Programa de Pós-Graduação em Engenharia de Produção) \\ saurin@vortex.ufrgs.br \\ Praça Argentina, no 9 - sala 402. CEP 90040-020. Porto Alegre - RS.
}
José Luis Duarte Ribeiro, Engo Civil, Dr. Professor e pesquisador do PPGEP/UFRGS ribeiro@vortex.ufrgs.br

\section{Resumo}

Este trabalho tem como objetivo avaliar como a segurança no trabalho é percebida pelos principais intervenientes na sua gestăo em um canteiro de obras (engenheiro, mestre-de-obra, técnico em segurança e operários). A coleta e o tratamento dos dados basearam-se em técnicas qualitativas, tendo sido realizadas nove entrevistas. Através da descriçāo e análise dos relatos foi caracterizada a percepção dos entrevistados em relação a nove tópicos: causas de acidentes, sugestōes para melhorar a segurança, satisfação no cargo, treinamento, principais riscos, carga de trabalho, principal prioridade, frequência de ocorrência de acidentes leves e quase-acidentes e nível de conscientizaçaáo quanto à segurança. As percepçôes indicaram diversas necessidades de melhoria gerencial, as quais influenciam de modo direto ou indireto a segurança no trabalho.

Palavras-chave: segurança no trabalho, construção civil, pesquisa qualitativa.

\section{Abstract}

The objective of this paper is to make an evaluation of how safety is perceived by people who should deal with it in a construction site. A qualitative approach was used to collect and analyze the data. Nine interviews were performed, including an engineer, a foreman, a consultant and six workers. Based on the description and the analysis of the interviews it was possible to understand their perception about nine issues: reasons for accidents, suggestions to improve safety, job satisfaction, training, main risks at work, main priority, work load, frequency of small accidents and near-misses, and level of safety awareness. Their perceptions uncover the need of managerial improvements, which may directly or indirectly contribute to improve the safety in the work site.

Keywords: safety, construction, qualitative research.

\section{Introdução}

Atualmente, tanto no Brasil quanto em países desenvolvidos, a construção civil continua a se destacar como um dos setores mais problemáticos no que diz respeito aos acidentes de trabalho. No Brasil, o setor é o quarto maior gerador de acidentes fatais em termos de freqüência e o segundo em termos de coeficiente por cem mil trabalhadores (Brasil, 1996). Em países como os Estados Unidos e a Inglaterra, as estatísticas também revelam a persistência de elevados índices de acidentes, o que tem despertado preocupação nas empresas, principal- mente em função do aumento dos prêmios dos seguros contra acidente (Gyi et al., 1999, Everett e Thompson, 1995). No Brasil, o seguro ainda não atua como fator de pressão, visto que o uso exclusivo do seguro estatal (que impõe igual taxação para todas as empresas) é predominante, ao contrário do que ocorre nos países citados, nos quais o seguro é controlado pelo setor privado e calculado com base em indicadores que refletem a realidade de cada empresa.

Embora os custos econômicos e sociais dos acidentes de trabalho sejam altos (Hinze, 1991), geralmente as empresas não procuram evitá-los através de abordagens 
PRODUÇÃO

sistemáticas, limitando-se ao cumprimento da legislação. Contudo, as normas brasileiras possuem um escopo restrito, focando principalmente na implantação de medidas relacionadas às instalações físicas de segurança (guarda-corpos ou aterramentos, por exemplo), e deixando de exigir medidas preventivas mais amplas que visem eliminar ou reduzir os riscos nas suas origens.

Atualmente, a principal norma internacional que aborda a segurança sob um enfoque sistêmico é a norma OSHA 18001 - Sistemas de Gestão da Segurança e Saúde no Trabalho - (De Cicco, 1999). Embora as empresas possam receber certificação pelo atendimento aos requisitos de tal norma, e talvez a mesma venha a originar uma norma similar às da série ISO 9000 e ISO 14000, o cumprimento da OSHA 18001 não implica necessariamente em redução de acidentes. Isto deve-se ao fato de que não há especificação de padrões mínimos de desempenho, mas apenas o estabelecimento de certos procedimentos gerenciais que a empresa deve adotar.

Assim, mesmo o cumprimento integral da legislação não é suficiente para uma redução significativa dos índices de acidentes, devendo-se encarar as leis como requisitos mínimos a serem cumpridos. Nos últimos anos, vêm sendo publicados diversos estudos que indicam a necessidade da adoção de medidas de caráter gerencial, as quais podem instrumentalizar ou complementar as exigências das leis.

Estudos realizados por Hinze (1997), Liska et. al. (1993) e Davies e Tomasin (1990), destacam a importância da existência de programas de segurança específicos para cada empreendimento. Nesses programas devem estar incluídos procedimentos tais como a colocação de metas relativas ao desempenho em segurança de cada obra, a coleta de indicadores, os incentivos aos operários para a redução de acidentes, a elaboração de orçamentos relativos à segurança, os programas de combate ao alcoolismo e o treinamento da mão-de-obra.

De acordo com Harper e Kohen (1998), as economias geradas pela implantação de um forte programa de segurança superam os custos do programa, atingindo uma relação custo-benefício favorável de 1,75:1 em um estudo de caso. A empresa na qual foi realizado tal estudo apresentava excelentes indicadores de segurança, adotando estratégias de gestão da segurança no trabalho que enfatizavam o envolvimento dos funcionários, a redução da rotatividade, programas $5 \mathrm{~S}$ (manutenção da limpeza e organização), reuniões semanais com as equipes de trabalho, identificação de riscos nos postos de trabalho preexistentes ao início dos serviços e fornecimento de equipamentos de segurança.

Baseando-se no desempenho de construtoras líderes nos EUA, Jaselskis et al. (1996) quantificaram os principais fatores que interferem na segurança. Entre os resultados desta pesquisa pode ser destacado: a necessidade de programas de segurança escritos e bastante detalhados (em média 4,5 páginas por atividade); a necessidade de apoio da alta direção da empresa; a realização de cerca de oito inspeções mensais formais de segurança em cada obra; a redução da rotatividade para um máximo de 7\%; o aumento dos gastos com premiações por desempenho em segurança para cerca de $9 \%$ do orçamento da segurança da obra; a realização de três reuniões formais com empreiteiros por mês.

Outro aspecto importante diz respeito às considerações das necessidades da segurança no trabalho desde a etapa de projeto do empreendimento (Hinze, 1997; Smallwood, 1996; Churcher e Starr, 1996). A viabilidade de incorporar estas necessidades ao projeto foi comprovada por Hinze e Gambatese (1996), os quais documentaram cerca de 400 soluções de projeto para melhorar a segurança nas obras.

Os poucos tópicos discutidos, envolvendo seguros, influência da legislação, do projeto, e escopo dos programas de segurança, representam apenas uma pequena parcela dos diversos elementos que interferem na gestão da segurança no trabalho, revelando a complexidade do problema. Assim, medidas pontuais e descoordenadas para gerenciar a segurança não são eficientes, e períodos sem ocorrência de acidentes serão devidos muito mais a fatores circunstanciais do que a tomada de ações preventivas. 
A influência de elementos como os citados sobre a segurança é geralmente considerada de forma superficial ou mesmo desconhecida por muitas empresas e profissionais, o que é reflexo, em parte, da falta de estudos científicos acerca de estratégias para gerenciamento da segurança. Nesse contexto, o presente artigo visa contribuir para a identificação e discussão de fatores de natureza gerencial que influenciam a segurança no trabalho, e que apesar de invisíveis, de modo oposto a falta de um guarda-corpo, por exemplo, também devem ser conhecidos e enfrentados, ainda que a legislação não se refira a sua existência.

\section{Método e Materiais}

\subsection{Técnicas de coleta de dados na área qualitativa}

O estudo de caso realizado seguiu uma abordagem essencialmente qualitativa. Apesar desse tipo de abordagem vir sendo utilizada com crescente intensidade em todas as áreas do conhecimento (Wolcott, 1994), ela ainda é pouco conhecida na área das Engenharias. De acordo com Mattar (1997), as pesquisas qualitativas são indicadas para identificar a presença ou ausência de algo, contribuindo para a elaboração de teorias sobre o fenômeno estudado. Assim, antes de apresentar o método de pesquisa utilizado, cabe comentar as técnicas de coleta de dados mais utilizadas na área qualitativa. Entre essas técnicas, destacam-se:

a) entrevistas individuais: essa foi a principal técnica utilizada no presente trabalho, em função de algumas características que pareceram apropriadas ao estudo. Inicialmente, foi considerado o fato de que a técnica favorece a livre expressão das posições individuais, característica relevante se levarmos em conta que as relações de trabalho na construção são geralmente autoritárias. Tendo isso em vista, considerou-se que entrevistas em grupo, envolvendo ou não pessoas de diferentes níveis hierárquicos, não seriam tão eficientes como as entrevis- tas individuais. Outra característica relevante da técnica é a possibilidade de maior controle do pesquisador sobre os dados coletados, uma vez que com entrevistas individuais torna-se mais fácil a exploração aprofundada de assuntos de interesse da pesquisa, incluídos ou não no roteiro de questões. Finalmente, outro fator que levou à escolha da técnica foi a possibilidade de realizar as entrevistas nos postos de trabalho, sem a necessidade da preparação prévia do local da entrevista, o que seria necessário caso a mesma fosse em grupo (Oliveira e Freitas, 1998).

b) grupos focalizados (entrevistas em grupo): nessa técnica, um pequeno grupo de pessoas é colocado em uma sala para discutir algum tópico de interesse da pesquisa. A discussão é conduzida por um moderador que busca seguir uma pauta básica, proporcionando, contudo, que os comentários feitos pelos participantes sejam incluídos na discussão do grupo (Churchill, 1995). De acordo com Oliveira e Freitas (1998), os grupos focalizados podem ser utilizados em associação com outras técnicas, contribuindo para o aprimoramento da pesquisa. Em relação a associação com as entrevistas individuais, Oliveira e Freitas destacam que a técnica pode auxiliar no planejamento do roteiro das entrevistas, agilizar a comparação entre diferentes grupos de participantes ou explorar pontos de vista que restaram obscuros após a realização das entrevistas.

c) observação participante: de acordo com Smith et al. (1991), o pesquisador pode assumir quatro papéis nesse tipo de levantamento: funcionário da organização, apresentando intensa participação e envolvimento com o ambiente pesquisado; envolvimento parcial, como um consultor, combinando participação no trabalho com entrevistas e observações; somente observador, com mínima comunicação com os pesquisados; explicitamente assumido como pesquisador, estando presente periodicamente nos locais de trabalho para desenvolver entrevistas e observações. Esse último papel foi o assumido na presente pesquisa, aproveitando-se para realizar observa- 
PRODUÇÃO

ções quando das ocasiões das visitas a obra para realizar as entrevistas.

d) questionários (surveys): este tipo de pesquisa utiliza-se de um questionário estruturado que em geral é submetido a um grande número de pessoas. Os questionários podem ser enviados pelo correio, por fax ou serem entregues pessoalmente. A participação do pesquisador no momento da coleta de dados é mínima, muitas vezes restringindo-se a explicar algum ponto do questionário que o respondente não tenha entendido. Uma das vantagens dessa técnica é a facilidade de realizar testes estatísticos, na medida em que o número de respostas coletadas costuma ser grande. De outro lado, os questionários são apropriados para abordar questões simples e diretas, não sendo apropriados para o levantamento de informações complexas e interrelacionadas.

\subsection{Método de pesquisa}

A fim de atingir o objetivo da pesquisa, foi realizado um estudo de caso em um canteiro de obras, buscandose identificar as percepções relativas à segurança no trabalho, tanto por parte da gerência (engenheiro, mestrede-obras e técnico em segurança) quanto por parte dos operários (profissionais e serventes). O planejamento da pesquisa foi estruturado nas seguintes etapas:

a) seleção da empresa: foi estabelecido que a empresa escolhida deveria atuar no subsetor construção de edificações e estar envolvida com a implantação de ações de melhoria tecnológica e gerencial, representando exemplos das melhores práticas no Rio Grande do Sul.

b) definição da amostra: as percepções foram obtidas através de entrevistas, tendo-se estabelecido no início do estudo que a amostra de entrevistados deveria incluir representantes dos níveis gerenciais e dos operários, sem no entanto definir rigidamente quantas pessoas seriam entrevistadas. Estabeleceu-se, como estimativa inicial, que seria necessário entrevistar um operário profissional, um servente, o mestre-de-obras, o técnico em segurança e o engenheiro.

c) elaboração dos roteiros de entrevistas: após a definição da amostra de entrevistados, a etapa seguinte foi o planejamento das entrevistas. Assim, foram elaborados dois roteiros de questões, um destinado aos níveis gerenciais e outro destinado aos operários, cada um contendo cerca de vinte questões. Os dois roteiros apresentam questões abertas divididas em duas seções, uma tratando da percepção acerca dos riscos no canteiro e outra tratando da percepção acerca das condições ambientais da obra. No item 2.3 são apresentados exemplos de questões incluídas nos roteiros.

d) realização das entrevistas: foi estabelecido que os roteiros deveriam ser utilizados em um segundo momento das entrevistas, para que inicialmente fossem abordadas questões genéricas sobre a rotina diária de trabalho. Isso possibilitou a discussão de assuntos que provavelmente não seriam abordados caso o roteiro fosse seguido rigidamente, embora tenha se tomado o cuidado de cobrir todos os assuntos pré estabelecidos. As entrevistas foram gravadas para assegurar o acesso completo as informações coletadas.

e) descrição dos dados: a etapa inicial do tratamento dos dados foi a descrição dos relatos, realizada em duas fases básicas. Inicialmente, fez-se a transcrição não literal das gravações, o que agilizou esta tarefa e facilitou a organização definitiva de cada relato. Após esta filtragem preliminar, os relatos foram organizados de forma coerente, incluindo, ocasionalmente, alguns comentários do pesquisador. Vale ressaltar que os relatos já constituem a percepção dos entrevistados, embora nessa etapa da pesquisa ainda não seja necessário identificar e classificar as percepções. 
f) identificação da estrutura de análise: com base na descrição dos relatos foi possível visualizar com maior clareza uma estrutura de análise dos dados. A estrutura de análise baseou-se na comparação das percepções entre o nível gerencial e o nível operacional, tendo sido definida a partir da constatação de que as percepções variavam principalmente entre os níveis hierárquicos, e não dentro de cada nível hierárquico. Na seção 3.2 é explicado em maiores detalhes o procedimento adotado para identificação da estrutura de análise, o qual permitiu uma análise organizada das percepções.

g) análise e interpretação dos dados: com base na descrição dos relatos foi realizada a análise e a interpretação dos mesmos. Embora não seja necessário e nem possível distinguir estas duas atividades, pode-se dizer que a análise é caracterizada por conclusões baseadas fortemente nos dados levantados, enquanto que a interpretação caracteriza-se por suposições baseadas mais na percepção do pesquisador do que em evidências concretas (Wolcott, 1994).

As etapas e, f, e g, podem ser entendidas como o método de análise de percepções adotado, o qual baseouse em recomendações genéricas para o tratamento de dados qualitativos (Wolcott, 1994), que não especificam uma determinada estrutura de análise. Considerou-se que tal definição não era apropriada a um levantamento dessa natureza, no qual a extensão quantitativa e qualitativa dos dados não pode ser prevista com precisão antes do estudo.

\subsection{Materiais}

As entrevistas foram. realizadas através de questionários constituídos por dois roteiros básicos de perguntas, um para engenheiro, mestre-de-obra e técnico em segurança (contendo vinte e uma perguntas) e outro para operários profissionais e serventes (contendo vinte e três perguntas). São apresentados, a seguir, alguns exemplos de questões do roteiro do nível gerencial: a) que riscos diferentes esta obra tem, em comparação com outras obras nas quais você já trabalhou? Há alguma pressão adicional nesta obra, em termos de custo ou prazo de conclusão?

b) a vizinhança, o meio ambiente ou pedestres correm algum risco decorrente desta obra?

c) qual é sua prioridade na rotina diária de trabalho?

d) poderia citar alguma decisão de projeto que dificultou a gestão da segurança neste canteiro? Poderia citar alguma decisão que facilitaria esta gestão, inclusive nas atividades de posterior manutenção?

Ao longo das diversas visitas ao canteiro para realizar as entrevistas, também foram realizadas observações informais acerca das condições do canteiro e comportamento dos operários, documentando-se algumas práticas através de fotografias. Além disso, ainda fez-se a análise de atas de reuniões da CIPA (Comissão Interna de Prevenção de Acidentes) e de fichas de investigação e análise de acidente de trabalho, utilizadas no âmbito desta comissão.

\section{Desenvolvimento do Método de Pesquisa}

\subsection{Realização das entrevistas}

De acordo com a expectativa inicial, as entrevistas com os níveis gerenciais foram as que consumiram mais tempo (cinqüenta minutos, em média), enquanto que as entrevistas com os operários foram mais rápidas e baseadas fortemente no roteiro de perguntas, demorando, em média, cerca de vinte e cinco minutos. Embora fosse esperado que as entrevistas com os operários tivessem menor duração, o conteúdo das mesmas ficou abaixo da expectativa do pesquisador.

À exceção do engenheiro, todas as outras entrevistas foram realizadas no próprio canteiro de obras, ocupando, ao menos parcialmente, o horário de expediente dos entrevistados. Nenhum deles ofereceu restrições ao uso de gravador, sendo que o único inconveniente foi, em 
PRODUÇÀO

algumas entrevistas, o ruído ambiental excessivo causado por serras e betoneira.

A etapa de entrevistas foi encerrada quando visualizou-se a existência de uma estrutura de análise, ou seja, uma forma de classificar os dados. Assim, foram realizadas nove entrevistas, três envolvendo representantes dos níveis gerenciais (engenheiro, mestre-de-obras e técnico em segurança no trabalho) e seis envolvendo representantes dos operários (dois operários profissionais e quatro serventes). Duas das entrevistas, uma com operário profissional e uma com servente, foram realizadas apenas para consolidar as visões anteriores, sendo propositalmente sucintas.

\subsection{Definição da estrutura de análise}

Ao contrário do que ocorreria caso tivesse sido aplicado um questionário fechado, a abordagem utilizada não possui uma estrutura de análise pré definida. Assim, procedeu-se uma leitura detalhada de todos os relatos a fim de identificar uma estrutura de análise que fosse representativa das percepções, que incluísse assuntos relevantes ao objeto de estudo e que facilitasse as atividades de análise e discussão.

Deste modo, buscou-se identificar a existência de assuntos mencionados por todos os entrevistados, e para os quais não houvessem mais de três respostas diferentes, podendo-se caracterizar poucas, claras e importantes percepções. Assim, foram selecionados nove tópicos: principal causa de acidentes, sugestões para melhorar a segurança no trabalho, satisfação no cargo, treinamento, atividades com maior risco de acidentes, carga de trabalho, principal prioridade, freqüência de ocorrência de acidentes leves e quase-acidentes e nível de conscientização dos operários.

Deve ser ressaltado que apenas as percepções relativas à carga de trabalho não foram obtidas a partir das questões dos roteiros, tendo o assunto sido levantado espontaneamente pelos entrevistados. De outra parte, percepções tais como a relativa à satisfação no cargo foram obtidas a partir das respostas à várias questões. Neste caso, as respostas à duas questões contribuíram para a identificação das percepções: a) como é a sua rotina de trabalho?; b) este canteiro é um local agradável para trabalhar, em termos de relações com colegas, instalações do canteiro, etc.?

Para cada um dos tópicos foi elaborada uma tabela de percepções, de modo a organizar e fornecer maior objetividade a discussão. Embora as tabelas tenham facilitado a tarefa de análise, deve ser esclarecido que as mesmas representam apenas um resumo dos dados levantados, os quais na realidade se constituem de todas as descrições dos relatos, das observações e da análise de documentos. A figura 1 apresenta um exemplo de tabela, referente ao tópico treinamento da mão-de-obra.

Após a elaboração das tabelas foi possível verificar que os tópicos podiam ser agrupados em duas categorias: tópicos com percepções semelhantes e tópicos com percepções diferentes entre o nível gerencial e o nível operacional. É importante esclarecer que essa estrutura de análise não é a única possível, tendo sido considerada a mais adequada pelos pesquisadores em função da natureza dos dados coletados. Teria sido possível, por exemplo, usar outras abordagens, como contagem de palavras ou discussão de eventos críticos. No entanto, os autores consideraram que essas abordagens não seriam tão eficientes quanto a usada. (Nota: a contagem de palavras é um método que permite identificar os tópicos fundamentais. Para tanto, são definidas palavras chaves, e a freqüência de ocorrência dessas palavras é um indicativo da importância do assunto para o entrevistado. A discussão de eventos críticos se baseia na identificação de alguns acontecimentos que os entrevistados consideram de maior importância. Esses acontecimentos, então, são amplamente discutidos em busca das suas causas e possiveis conseqüências). 
4. Resultados e Análise dos Dados

4.1. A empresa e a obra do estudo de caso

O estudo de caso foi realizado em uma construtora de pequeno porte, localizada na cidade de Porto Alegre (RS). Excluindo alguns serventes, a maioria da mão-deobra operária é terceirizada, dividida entre diversos empreiteiros.

A empresa é certificada pela norma ISO 9002 e desde 1996 vêm mantendo programas $5 \mathrm{~S}$ em todas as obras, além de vir desenvolvendo outras ações de melhoria ao longo dos últimos anos. Com base nestas caracteristicas, pode-se considerar que a empresa destacase positivamente no setor em termos de avanços gerenciais e tecnológicos, enquadrando-se nos critérios de seleção definidos no item 2.1.

A obra do estudo é um edifício residencial de nove pavimentos, localizado em um canteiro com baixa taxa de área construída, o que facilita o planejamento do seu arranjo físico. No período da pesquisa a empresa possuía cinco obras em execução, sendo que a obra do estudo possuiu, em média, trinta e cinco funcionários (quatro da empresa e o restante de empreiteiras).

\subsection{Tópicos com percepção semelhante entre os} níveis hierárquicos

Os quatro tópicos com percepção semelhante entre os níveis hierárquicos foram relativos a principal causa de acidentes, sugestões para melhorar a segurança, satisfação no cargo e treinamento da mão-de-obra.

Relativamente à principal causa de acidentes, os entrevistados foram unânimes em apontar a própria vítima como principal responsável pelo acidente, baseando-se na percepção de que ela assumiu o risco praticando ação insegura. Estas respostas consideraram somente a causa mais visível do acidente, ou a última ação de uma cadeia de eventos, ficando evidente que alguns dos acidentes descritos pelos entrevistados foram decorrência de outras causas anteriores a ação insegura, tais como falta de treinamento ou não cumprimento da norma NR18 - Condições e Meio Ambiente de Trabalho na Indústria da Construção - (Fundacentro, 1995). Um relato de acidente com choque elétrico na betoneira ilustra esta afirmação, visto que o fato dos operários terem arrastado a betoneira sobre seu próprio cabo de energia não provocaria um acidente, ao menos tão grave como ocorreu, se o equipamento estivesse aterrado.

A falta de citação de outras causas para a ocorrência dos acidentes pode ser explicada pela inexistência de procedimentos estruturados para a investigação de acidentes ocorridos na empresa, deficiência constatada a partir da análise de atas das reuniões da CIPA. Em uma destas atas, por exemplo, a queda de um operário de um andaime durante a execução de serviços no teto de um apartamento, foi explicada de modo simplista com a seguinte expressão: ${ }^{2} 0$ operário não olhou para trás ${ }^{2}$.

Ainda em relação a este tópico, é importante registrar que nenhum entrevistado manifestou preocupação ou consciência das diversas condições inseguras verificadas na obra, ficando evidente a tendência de relegar este fator a um plano secundário na prevenção de acidentes.

O segundo tópico no qual as percepções foram semelhantes é relativo a proposição de sugestões para melhorar a segurança na obra. Nenhum dos entrevistados apresentou qualquer proposta, havendo, contudo, reclamações quanto à dificuldade de execução dos serviços de alvenarias e fôrmas na cobertura, revelando insatisfação com as decisões dos projetistas. A conscientização acerca dos riscos destes serviços provavelmente se deve a um acidente ocorrido poucos dias antes do início da pesquisa, no qual um trecho da alvenaria de periferia na cobertura ruiu e os materiais atingiram uma área de circulação de pessoas no pavimento térreo (ocorreram somente danos materiais). Outra resposta que mereceu atenção é a de um operário o qual propôs o fornecimento de vale-transporte pela empresa. Este benefício contribui indiretamente para melhorar a produtividade e a redução de acidentes, visto 
PRODUÇÃO

que os funcionários chegam menos cansados ao canteiro, poupados de longos trechos de caminhadas.

As sugestões poderiam ter incluído, por exemplo, melhorias relacionadas às decisões de projeto, melhores equipamentos ou adaptações em tecnologias construtivas. Com base na falta de conhecimento acerca das questões de segurança demonstrada pelos entrevistados, pode-se supor que práticas como caixas de sugestões relativas à segurança não teriam o resultado desejado nesta obra, visto que os operários tenderiam a se preocupar com melhorias de caráter básico, tais como o citado exemplo de fornecimento de vale-transporte.

Apesar da constatação de que sugestões espontâneas e facilmente transferíveis à prática são improváveis, a experiência dos entrevistados pode ser aproveitada através de outras estratégias. Neste sentido, boas oportunidades para que gerentes e operários proponham melhorias na prevenção de acidentes são no âmbito das reuniões de planejamento da produção e das avaliações de risco.

As entrevistas também revelaram a insatisfação dos funcionários no cargo. A insatisfação do engenheiro e do mestre-de-obras pode ser, ao menos parcialmente explicada, pela carga excessiva de trabalho e pela falta de perspectivas de crescimento profissional dentro da empresa. Já os operários que se manifestaram insatisfeitos destacaram que o trabalho na construção não decorre de opção pessoal, mas sim de sua pouca qualificação, condição que impediu o ingresso em outros setores da economia. Apesar do canteiro ser relativamente limpo, a sujeira da obra foi mencionada como fonte de insatisfação pelo engenheiro e por um servente.

As deficiências no processo de treinamento da mãode-obra também ficaram evidentes nas entrevistas. A gerência apontou a alta rotatividade da mão-de-obra empreitada como principal justificativa para o pouco treinamento, adotando postura conformista em relação a esta restrição. Alguns trabalhadores também relataram a falta de qualidade do pouco treinamento que recebem. De acordo com os relatos, o treinamento foi ministrado pelo mestre-de-obras ou pelo chefe dos empreiteiros, resumin-

do-se a uma indicação de quais EPI (Equipamentos de Proteção Individual) usar, sem maiores explicações acerca de situações e procedimentos de uso.

Também mereceram atenção as respostas de dois trabalhadores, os quais dispensariam o treinamento devido a sua larga experiência na função. Tais respostas podem representar um grupo de funcionários com esta mesma percepção e podem ser explicadas pela significativa experiência de ambos (um tem vinte anos e o outro tem dez anos de trabalho na construção civil) e pelo fato de desempenharem funções especiais na obra (encarregado da equipe de carpinteiros e guincheiro, respectivamente). Contudo, estes mesmos trabalhadores também relataram que receberam pouco treinamento ao longo de suas carreiras, podendo-se concluir que esta deficiência explica a valorização excessiva da experiência e a indiferença em relação as condições inseguras.

\subsection{Tópicos com percepção diferente entre os} níveis hierárquicos

Os cinco tópicos nos quais as percepções entre os níveis hierárquicos foram diferentes incluem as atividades de maior risco, carga de trabalho, principal prioridade, freqüência de ocorrência de pequenos acidentes e nível de conscientização dos operários em relação à segurança.

Como era esperado devido a grande quantidade de atividades de risco em canteiros de obra, este tópico foi o que recebeu o maior número de respostas. De modo geral, pode-se afirmar que o nível gerencial tende a possuir uma visão mais ampla acerca dos riscos no canteiro, visto que seus integrantes citaram um maior número de riscos. Neste nível, merece destaque a menção unânime aos riscos nos serviços na cobertura, os quais, segundo alguns entrevistados, poderiam ter sido evitados ou minimizados por decisões de projeto.

Já entre os operários, verificou-se a tendência em dispensar maior atenção aos riscos mais visíveis e ligados as suas funções, tais como serviços em andaimes (três operários citaram somente este risco) e circulação no 
pavimento térreo (área sujeita a queda de materiais). Os outros riscos citados pelos entrevistados foram os serviços em telhados, serviços que envolvem manuseio de cimento, serra circular, elevador de carga e manuseio de bombas de concretagem. Neste tópico também destacou-se a unanimidade, entre gerência e operários, acerca da importância dos riscos nos serviços em andaimes suspensos.

Embora o roteiro de questões não incluísse uma pergunta especificamente relacionada à carga de trabalho, $o$ assunto foi levantado espontaneamente pelo engenheiro e pelo mestre-de-obras, os quais enfatizaram a existência de uma rotina estressante na qual há pouco ou nenhum tempo para tarefas de treinamento de pessoal ou planejamento das atividades. No caso do engenheiro, a carga de trabalho excessiva decorre do montante de tarefas burocráticas ( $90 \%$ do dia, segundo sua estimativa). De outra parte, no caso do mestre-de-obras as causas estão relacionadas à pressão exercida pelo engenheiro e à dificuldade de gerenciar os operários (30\% são irresponsáveis e de difícil trato, segundo sua estimativa).

As percepções também divergiram no tópico relativo à principal prioridade no trabalho, ou seja, a principal preocupação na rotina diária. A segurança no trabalho não foi mencionada como prioridade por nenhum dos entrevistados, tendo sido verificado que a prioridade dos entrevistados está relacionada a forma pela qual eles são avaliados, formal ou informalmente, pelo nível hierárquico imediatamente superior. Assim, o engenheiro prioriza prazo e custo pois recebe premiações se concluir a obra no prazo previsto, sendo ainda cobrado pela diretoria quanto ao cumprimento do orçamento. Embora não receba premiações, o mestre-de-obras também prioriza o cumprimento dos prazos, principalmente como reflexo das prioridades do engenheiro.

De outra parte, os operários foram unânimes em afirmar que a limpeza da obra é sua principal preocupação. Tal prioridade é conseqüência da cobrança insistente do mestre-de-obras em relação a este aspecto, assim como do fato da limpeza ser um dos itens de avaliação do programa 5S, o qual possibilita premiações aos operários.
Também foi possível identificar a percepção dos entrevistados quanto à frequeência de ocorrência de acidentes leves (sem afastamento) e quase-acidentes. Os quase-acidentes são também conhecidos como incidentes, e referem-se a acidentes que não envolveram nenhuma lesão em alguém ou prejuízo material à empresa, embora tenham apresentado potencial para tanto (Hinze, 1997). Um exemplo de quase-acidente pode ser a queda de uma ferramenta de um pavimento alto, mas que não danificou a mesma e nem atingiu nenhuma pessoa.

Neste tópico, enquanto o nível gerencial considerou comum a ocorrência deste tipo de acidente, os operários consideraram rara a ocorrência dos mesmos. É pressuposto do trabalho que os acidentes leves ocorrem com freqüência significativa na construção civil. No Brasil não há estatísticas a respeito da freqüência destes acidentes, já que os números oficiais são baseados nas CAT (Comunicação de Acidente de Trabalho), as quais geralmente só registram acidentes com afastamento superior a quinze dias. Entretanto, os preocupantes números decorrentes das CAT (Costella, 1999), permitem supor que acidentes leves ou quase- acidentes são comuns. De acordo com Heinrich apud Laufer e Ledbetter (1986), há uma relação de trezentos casos de quase-acidente para trinta casos de lesões menores (primeiros-socorros) e um caso que resulte em dia perdido ou necessidade de auxílio médico.

Pode-se supor que a percepção dos operários é resultado do pouco contato com outras obras (ao contrário, principalmente, do engenheiro e do técnico em segurança) e, possivelmente, do fato de que muitos acidentes leves não chegam ao conhecimento da maioria dos operários, já que não há registro formal nem divulgação de acidentes que exigem um tratamento simples no próprio canteiro. Assim, a percepção dos operários decorre de fatores não gerenciáveis por eles (treinamento e fornecimento de EPI, por exemplo) e contribui para o desprezo das questões de segurança e para a ocorrência de ações inseguras, visto que muitos deles consideram que os acidentes de trabalho são fatos distantes de sua realidade, improváveis de acontecer com eles. 
PRODUÇÃO

Finalmente, as percepções também divergiram no que diz respeito ao nível de conscientização dos operários em relação à segurança. A conscientização foi avaliada a partir de respostas acerca de uso de EPI, reconhecimento de riscos, iniciativa para eliminar condições inseguras, iniciativa para alertar os colegas acerca de atitudes de risco e preocupação com a organização do canteiro.

Os operários julgaram a si próprios e aos colegas como conscientizados na maioria, o que demonstra certa tolerância com atos e condições inseguras, situações que foram observadas com facilidade na obra do estudo. Apresentando percepções mais coerentes com a realidade observada pelo pesquisador, o engenheiro e o mestre-deobras reconheceram a existência de dois grupos de funcionários, os conscientizados e os não conscientizados. A partir destas percepções, esperava-se que algumas das entrevistas revelassem operários não conscientizados, os quais poderiam ter mau relacionamento com colegas ou demonstrar falta de conscientização à respeito da importância de uso de EPI ou limpeza. Embora nenhum dos entrevistados tenha se enquadrado no grupo dos não conscientizados, alguns deles reconheceram a existência deste tipo de funcionário, relatando que as ações de furto e vandalismo, em especial, são relativamente comuns.

Na percepção do pesquisador, embora ações como estas sejam praticadas por uma minoria, elas terminam por prejudicar a imagem da maioria dos operários, contribuindo para a disseminação de preconceitos em relação à mão-de-obra do setor. Os relatos dos operários demonstraram que os mesmos têm a intenção e julgam trabalhar de forma organizada e segura, porém tais percepções não correspondem à realidade, em grande parte, pela ausência de planejamento e monitoramento da segurança no trabalho nas empresas.

Em uma análise conjunta de todos os tópicos, podese verificar que os próprios gerentes (engenheiro e mestre-de-obras) também não são conscientizados, visto que dedicam pouco tempo aos assuntos de segurança, ignoram as causas de muitos acidentes e há certo conformismo com os níveis de desempenho atuais.

\section{Outras Percepções Importantes}

Além dos tópicos discutidos no item anterior, as entrevistas também revelaram outras percepções que não se enquadram na estrutura de análise estabelecida, mas que também indicam obstáculos para a melhoria da segurança no canteiro.

Inicialmente, os relatos do engenheiro e do mestrede-obras revelaram que a atuação do técnico em segurança deveria ser reavaliada pela empresa, visto que sua contribuição tem sido insuficiente. A insatisfação decorre da forma de trabalho atual do técnico, que atua como prestador de serviços, fazendo apenas uma visita à obra a cada quinze dias, com duração em torno de uma hora. As explicações do técnico ao longo da visita, consideradas uma forma de treinamento por ele, são úteis mas perdem o efeito devido a descontinuidade da orientação.

As entrevistas no nível gerencial também revelaram que a atuação da CIPA é insatisfatória, considerando-se que as reuniões da comissão rendem poucos resultados práticos. A ineficiência da CIPA tem origem na falta de apoio da direção da empresa à comissão e à segurança de modo geral, tendo sido relatado que exigências simples, como aquecedores de refeições ou trava-quedas para cintos de segurança, demoram muitos meses para serem atendidas.

Todas as deficiências reveladas através das percepções deixam evidente a falta de uma abordagem estruturada para gerenciar a segurança nas obras. Durante as entrevistas, o técnico em segurança foi o único a reconhecer explicitamente a necessidade desta abordagem, afirmando que a atuação da empresa está muito voltada a resolução de pequenos problemas do dia-a-dia da obra, os quais apenas representam as conseqüências da falta de medidas preventivas mais amplas e melhor planejadas. 


\section{Conclusões}

Este trabalho tratou de identificar, através do uso de técnicas qualitativas de coleta e tratamento dos dados, as percepções dos operários e da gerência em relação à segurança no trabalho em um canteiro de obras. As percepções revelaram diversos problemas na gestão da segurança do trabalho na empresa, os quais provavelmente são comuns, ou até mesmo mais graves, na maioria das empresas do setor. A origem das deficiências pode ser atribuída a não priorização da segurança pela alta direção, o que se reflete diretamente na ausência de gerenciamento estruturado da segurança e na pouca compreensão de gerentes e operários quanto ao assunto.

No estudo foram identificados obstáculos que devem ser superados para a melhoria do desempenho em segurança, destacando-se, entre eles, a pouca quantidade e qualidade do treinamento à mão-de-obra, a alta rotatividade da mão-de-obra empreitada, a falta de apoio da alta direção à CIPA, o pouco tempo que o técnico em segurança dedica à empresa e a falta de registro formal e investigação de acidentes e quase-acidentes.

Além disso, algumas percepções demonstraram que os níveis gerenciais também devem receber treinamento, visto que estes, assim como os operários, nada tinham a sugerir para melhorar a segurança e tendiam a responsabilizar os funcionários pelos acidentes. A insatisfação no cargo em nada contribui para a melhoria da segurança na obra, assim como a carga excessiva de trabalho da gerência, o que inviabiliza as tarefas de planejamento. As estratégias para cumprir as metas de prazo e custo (prioridades da gerência) seriam mais eficientes e realistas se reconhecessem que os cuidados com a segurança podem ser decisivos para o sucesso nestas áreas.

Os esforços destinados à mudança de mentalidade dos operários devem alertá-los para o reconhecimento de que é falsa a sensação de segurança que transpareceu nas entrevistas. Os poucos riscos identificados, o fato de se julgarem suficientemente conscientizados, a percepção de que ocorrem poucos acidentes e a percepção de que eles são os principais culpados pelos mesmos, são reflexos da falta de treinamento e conscientização e não coincidem com a realidade observada nas obras.

Os resultados do estudo ainda contribuíram para a identificação de potenciais de pesquisa na área. São exemplos, o desenvolvimento de procedimentos para a identificação de posturas de operários e gerentes em relação aos riscos de acidentes, o desenvolvimento de mecanismos que utilizem a experiência dos operários na gestão da segurança, o desenvolvimento de estratégias para motivar gerentes e operários em relação à segurança e levantamentos acerca de reais índices de quase-acidentes e seus respectivos custos em canteiros de obras.

\section{Referências Bibliográficas}

BRASIL. Ministério do Trabalho. Secretaria de Segurança e Saúde no Trabalho. Campanha nacional de combate aos acidentes de trabalho (CANCAT). Brasília, 1996.

CHURCHER, D.; STARR, G. Incorporating construction health and safety into the design process. In: INTERNATIONAL CONFERENCE OF CIB WORKING COMMISSION W99, 1, 1996, Lisbon. Proceedings... p. 29-40, Rotterdam: A.A. Balkema, 1996.

CHURCHILL, G. A. Marketing research: methodological foundations. Dryden Press, 1995.

COSTELLA, M. Análise dos acidentes do trabalho e doenças profissionais ocorridos na atividade de construção civil no Rio Grande do Sul em 1996 e 1997. Porto Alegre, 1999. Dissertação (Mestrado em Engenharia) Escola de Engenharia, CPGEC/UFRGS.

DAVIES, V.J.; TOMASIN K. Construction safety handbook. London: Thomas Telford, 1990. 
PRODUÇÃO

DE CICCO, F. Manual sobre sistemas de gestão da segurança e saúde no trabalho: volume III. São Paulo:

Risk tecnologia, junho, 1999.

\section{EVERETT, J.; THOMPSON, W. Experience}

modification rating for workers' compensation insurance. Journal of Construction Engineering and Management, v. 121, n. 1, p. 66-79. Mar 1995.

FUNDACENTRO. Condições e meio ambiente de trabalho na indústria da construção: NR-18. Brasília, 1995.

GYI, D.; GIBB, A.; HASLAM, R. The quality of accident and health data in the construction industry: interviews with senior managers. Construction Management and Economics, v.17, p. 197-204., 1999.

HARPER, R.; KOEHN, E. Managing industrial construction safety in southeast Texas. Journal of Construction Engineering and Management, v.124, n.6, p. 452-457. Dec 1998.

HINZE, J. Indirect costs of construction accidents. Austin: The Construction Industry Institute, 1991.

HINZE, J.; GAMBATESE, J. Addressing construction worker safety in project design. Austin: The Construction Industry Institute, 1996.

HINZE, J. Construction safety. Englewood Cliffs: Prentice-Hall, 1997.

JASELSKIS, E.; ANDERSON, S.; RUSSEL, J. Strategies for achieving excellence in construction safety performance. Journal of Construction Engineering and Management, v. 122, n.1, p. 61-70. Mar 1996.

LAUFER, A.; LEDBETTER, W. Assessment of safety performance measures at construction sites. Journal of Construction Engineering, v.112, n.4, p. 530-542. Dec 1986.

LISKA, R.W. et al. Zero accident techniques. Austin: The Construction Industry Institute, 1993. 292 p.

MATTAR, F. N. Pesquisa em marketing. São Paulo: Atlas, 1997. v.1.

OLIVEIRA, M.; FREITAS, H. Focus group pesquisa qualitativa: resgatando a teoria, instrumentalizando o seu planejamento. Revista de Administração, v. 33, n. 3, p. 83-91. Jul/set 1998.

SMALLWOOD, J. The influence of designers on occupational health and safety. In: INTERNATIONAL CONFERENCE OF CIB WORKING COMMISSION W99, $1^{\circ}$, 1996, Lisbon. Proceedings... p. 203-214, Rotterdam: A.A. Balkema, 1996.

SMITH, M.; THORPE, R.; LOWE, A. Management research: an introduction. Thousand Oaks, California: Sage, 1991.

WOLCOTT, H. Transforming qualitative data: description, analisys and interpretation. Thousand Oaks, California: Sage, 1994. 


\begin{tabular}{|l|c|c|c|}
\hline & $\mathrm{R} 1$ & $\mathrm{R} 2$ & $\mathrm{R} 3$ \\
\hline Engenheiro & $\mathrm{X}$ & & \\
\hline Mestre-de-obras & $\mathrm{X}$ & & \\
\hline Técnico em segurança & $\mathrm{X}$ & & \\
\hline Operário profissional 1 & & & $\mathrm{X}$ \\
\hline Operário profissional 2 & & $\mathrm{X}$ & \\
\hline Servente 1 & & & $\mathrm{X}$ \\
\hline Servente 2 & & $\mathrm{X}$ & \\
\hline Servente 3 & & $\mathrm{X}$ & \\
\hline
\end{tabular}

R1: o treinamento é insuficiente, como decorrência da alta rotatividade de mão-de-obra ou de negligência da empresa.

$\mathrm{R} 2$ : o treinamento se resumiu a uma indicação de quais EPI usar e/ou curso ocasional ministrado pela CIPA, de forma que pode ser considerado insuficiente.

R3: não precisa receber treinamento, pois tem experiência.

Fig. 1. Percepções dos entrevistados em relação ao treinamento de mão-de-obra. 